\title{
Poverty Levels among Local Municipalities in the NMMD of South Africa: A Multidimensional Scaling Approach
}

\author{
Kgomotso Charlene Mahole
} North West University, Mmabatho, 2735
tso.mahole@gmail.com

\section{Ntebogang Dinah Moroke}

North West University, Mmabatho, 2735 Ntebo.Moroke@nwu.ac.za

Nehemiah Mavetera, Ph.D

North West University, Mmabatho, 2735 Nehemiah.Mavetera@nwu.ac.za

Doi:10.5901/mjss.2014.v5n2p549

Abstract

The North West Province has four district municipalities which are in turn subdivided into local municipalities. The province is experiencing very slow service delivery levels yet every year each municipality is allocated funds to ensure its smooth running. Although government avails funds, allocates poverty grants to the community and has black empowerment strategies in place, the communities in this province still remain poor. Many reasons can be cited for this status quo, ranging from mismanagement of funds, low resources, insufficient funds and the number of municipalities. This study recommends possible solutions to these problems. Data for the five local municipalities from the Ngaka Modiri Molema District Municipality (NMMDM) was analysed using Multidimensional scaling technique. Each municipality is defined by ten variables measuring poverty. The technique grouped the five local municipalities of the NMMDM into two clusters of local municipalities. An optimal perceptual map identified the levels of municipalities according to their poverty levels. With this information, the NMMDM can formulate appropriate strategic plans and policies that can address the local municipalities. Also the NMMDM can be able to address the targets set for the MDG goals of eradication of extreme poverty and hunger.

Keywords: Poverty levels, Local municipalities, Ngaka Modiri Molema District, Multidimensional scaling, South Africa

\section{Background of municipalities in the North West Province}

The government of the Republic of South Africa (RSA) consists of a central government, nine regional governments (provinces) and a total of 262 local governments (municipalities). As Devenish (2005) explained, although local government constitutes the third tier or sphere in the hierarchy of government, it is most certainly not unimportant. Its manifestation in the form of local municipalities or councils is perceived as a cornerstone of contemporary democratic government. De Villers (2008) defines local government as comprising of local community management and administration. As such, it is that branch of government and administration that is most intimately concerned with the lives of ordinary people and with those matters that are closest to them in their daily experience and basic needs.

As alluded in Devenish (2005), the South African Constitution accords to local government the following five kindred objectives:

- to furnish a system of democratic and accountable government for local communities;

- to ensure the provision of services to communities in a sustainable manner;

- to promote social and economic development;

- to promote a safe and healthy environment; and

- to encourage the involvement of communities and community organizations in matters of local government.

These objectives present a formidable challenge to the municipal leaders particularly in some disadvantaged communities where there is a dearth of human resources and skills. These skills are very essential for effective local 
governance. The executive and legislative authority of a municipality is vested in its municipal council. The municipality has the right to govern, on its own initiative, the local government affairs of its community, subject to the relevant national and provincial legislation as provided in the Constitution. The Constitution together with Chapter 5 of the Municipal Systems Act, 2000 (Act 32 of 2000) has a substantial impact on the traditional role of local governments. In addition to providing municipal services, municipalities must (by law) be developmentally oriented and adopt the Integrated Development Plan (IDP) set by the state to give an overall framework for development.

The Ngaka Modiri Molema District Municipality (NMMDM) is one of the four district municipalities of the North West Province of RSA. The other three district municipalities are: Bojanala-Platinum, Dr Ruth Segomotsi Mompati and Dr Kenneth Kaunda. The NMMDM covers an area of 31039 square $\mathrm{km}$ and shares an international border with the Republic of Botswana. It comprises of five local municipalities, namely: Mafikeng, Ratlou, Ramotshere Moiloa, Ditsobotla and Tswaing. Poverty eradication, local economic development, job creation and generally the promotion of reconstruction and development are important missions set by the municipality to be achieved with assistance from the national and relevant provincial government. An estimated total of 554668 people live under the minimum living income of just above R900.00 per month in the NMMDM. This is equivalent to $29 \%$ of the total number of earners of minimum living income in the North West Province. This makes the district one with the most underprivileged people in the North West Province (NMMDM Report, 2010).

Due to these stipulations, poverty eradication has become one of the most important issues in the NMMDM together with issues of socio-economic development and income distribution. The latter is generally viewed as a matter of public concern especially to the municipality. Income distribution determines the spending power of citizens. Without equitable distribution of income, communities will largely be affected by poverty. The rich will get richer, while the poor get poorer. The NMMDM society is characterised by extreme poverty and inequality in the distribution of income and earning opportunities. There are presumably many factors that could contribute to this problem. Some would argue that the free market system tends to reward those who already 'have' and discriminate against the 'have-nots'.Others would blame it on lack of economic growth pointing to the fact that rising levels of per capita income usually go hand in hand with an improvement in the personal distribution of income.

Lack of employment opportunities and the consequential income disparity bring about mass poverty in most parts of these communities. Unemployment is a result of various factors and tends to mostly affect the less skilled and the lowpaid. Therefore, NMMDM in a bid to improve the lives of the poor as a district municipality remains the most appropriate governance level since it is the sphere of government closest to the people.

\section{Statement of the Problem}

The NMMDM is a predominantly rural region, where the majority of its population live. The communities residing in those rural areas are more severely affected by aspects such as poverty and unemployment. These communities suffer from low levels of income and spending power, which results in very low standards of living. The identification and formulation of appropriate strategic plans and policies of poverty eradication by the NMMDM is determined by the appropriateness of the available information. However, the NMMDM does not have at hand data and information regarding the poverty levels in these municipalities. In addition, they do not know, if any, the similarities amongst these municipalities with regard to poverty levels. It is proposed that MDS can be used to divide the five local municipalities of the NMMDM into pairs according to their similarities in poverty levels.

\subsection{Study Objectives}

As stated in the problem statement section, three objectives were elicited for this study namely:

- To determine the levels of poverty in the local municipalities.

- To determine similarities among local municipalities

- To identify the number of local municipalities with similarities and later group them.

The results of the study have to be understood within the context of the development challenges facing the local government as well as the required interventions. It is also proposed that by identifying these similarities, the municipal authorities can be able to manage the problems associated with poverty in these municipalities. 


\section{Characteristics of Data Used in the Study}

The deprivations around poverty are not just about low incomes but include loss of human dignity which is about human suffering. There is also poverty in terms of denial of access to opportunities for advancement. That is particularly telling since we live in the world in which, on one hand, there are huge material and natural resources at our disposal, as well as dramatic technological advances, and yet, on the other hand, there are inequalities and uneven distribution of wealth resulting from the consequences of poverty which we see in the face of women, children, people with disabilities, the elderly, migrants and refugees (Ndungane, 2003).

At the United Nations Millennium Summit in 2000, the international community reached consensus on working to achieve eight critical economic and social development priorities by 2015 (Lehohla, 2010). The eight development priorities were termed the Millennium Development Goals, (MDGs) under the Millennium Declaration signed by 189 countries.

The eight MDGs are in numerical order:

- To eradicate extreme poverty and hunger.

- To achieve universal primary education.

- To promote gender equality and empower women.

- To reduce child mortality.

- To improve maternal health.

- To combat HIVIAIDS, malaria and other diseases.

- To ensure environmental sustainability.

- To develop a global partnership for development.

The reduction of poverty and hunger is at the top of the list because it is the central objective to which the other MDGs must contribute in one way or another. The poverty target occupies a position of central importance in the MDGs. As such, the effort to combat extreme poverty is closely related to virtually all other goals.

Poverty is a multi-dimensional phenomenon. It refers to the lack of options with respect to a number of dimensions such as quality of life and actions geared towards eradicating it. The MDGs have identified the following targets for addressing Extreme Poverty and Hunger under MDG by 2015:

- halve the proportion of people whose income is less than a dollar a day;

- halve the proportion of people who suffer from hunger; and

- achieve full and productive employment and work for all, including women and young people.

The key indicator for this goal is a dollar a day. This measure has been revised upwards over time to take into account the changing cost of living. For low-income countries, the target was a dollar a day, whilst for middle-income countries the measure was set at $\$ 2.50$ a day. Whilst RSA is classified as a middle-income country, its society is very uneven. The majority of the population qualify the country as a low-income country (Lehohla, 2010). It is to this part of society that government interventions are targeted and it is in this sector where the MDG 1 is applicable. As a member state of the United Nations, RSA is a signatory to this agreement. RSA is fully committed to fulfilling its constitutional obligations to deliver socio-economic rights within the context of its national plan of action and the MDGs. One of RSA's indications of progress towards the achievement of the MDGs is the effective and equitable delivery of public services.

Poverty is an ever-present reality in contemporary RSA. The distribution of wealth in the country is heavily skewed towards the rich. Despite a radical increase in social welfare over the last decade and a half, the vast majority of households remain poverty stricken. While the poor are heavily reliant on the state for income in the form of social grants, the majority of people are not eligible for them. This means that the meagre income derived from grants has to support many people beside their intended beneficiaries (Mosoetsa, 2011). A quarter of South Africans are jobless in terms of the official definition of unemployment. When the entire economically active population is taken into account, however, the figure rises to a staggering 32 per cent. Unemployment is likely to get even worse as waged employment declines further. Poor households are sites of both instability and conflict. In the absence of waged employment, working class households are the only source of security for many of the poor (Mosoetsa, 2011).

Many organizations in RSA have signed a Declaration of War on Poverty. These include Churches, nongovernmental organizations (NGOs), government, trade unions, the UN and, significantly, homeless people's organizations representing grassroots communities (Ndungane, 2003). The declaration describes poverty and its effects, opening with words that are relevant to us all: "The war on poverty and inequality is RSA's most important priority and the greatest challenge." Eradicating poverty is essential to consolidate the gains of democracy in the RSA. Necessary steps include finding solutions to unemployment and landlessness, increasing access to credit for the poor and encouraging 
small-scale production and entrepreneurship in the formal and informal sectors. The gap between high-income earners and low-paid workers must be addressed as well as the situation of the working poor. Children in situations of poverty, those with disabilities, older persons and other vulnerable groups need special attention (Ndungane, 2003)

Efforts by the provincial governments to alleviate poverty and ensuring that the communities continue to have sustainable livelihoods have intensified over the years. Provincial governments are committed to strengthening food security and eliminating hunger through skills development and empowerment (Madiba, 2012). It is the responsibility of the provincial government to provide a social safety net to the most vulnerable members of society. Projects to provide a social safety net are complemented by efforts to reduce dependency on the social grant system. President Jacob Zuma said during his 2012 State of the Nation Address, "More than 8 million learners benefit from government's school feeding scheme", (Govender, 2012). The National School Nutrition Programme (NSNP) was started in 1994. Previously known as the Primary School Nutrition Programme, NSNP was extended in 2009 to serve secondary schools as well. Many of the children who receive the food are orphans or very poor.

The NSNP programme also created job opportunities for many who were unemployed. These jobs are created through contracting different service providers in the form of small medium and macro enterprises (SMMEs) (Govender, 2012). Government has given private and public institutions the two per cent employment equity target of people with disabilities (Khumalo, 2012). This is to ensure equal access to all services and opportunities and that people with disabilities are well represented in all departments. The mandate was developed to promote, facilitate, coordinate and monitor the realisation of the rights of the vulnerable groups. Since 1994, local government has become a more important sphere than before. It is bigger than it once was. It has been described as the 'hands and feet' of government, and is expected to play a key role in developing its areas (Sithole et al., 2007). Like national government, local government must carry through the commitment to eradicate extreme poverty and hunger.

Internationally, there is some debate about whether decentralisation to local government helps to empower communities by making government closer and more accessible to them, or whether it undermines rights won at national level. A form of decentralisation is occurring in the RSA with the strengthening of local government and the introduction of integrated development plans (IDPs), which are meant to give strategic direction both to the work of the municipality and to national and provincial government operating in its area (Sithole et al., 2007)

Decentralisation has become part of the standard policy recipe for good governance, promoted by agencies such as the World Bank and the United Nations. Decentralisation fosters participatory democracy and results in more responsive service delivery, attuned to local needs. It benefits poverty stricken communities, since local government is more accessible and deals with issues of central importance to them (Sithole et al., 2007)

More often, local institutions are more accountable to central government than to local electorate because local government may be dominated by local elites. The poor and other marginalised groups may not have the political and organisational resources to influence local decision making. Although local government in the RSA still accounts for a smaller share of expenditure than provincial or national government, it is now much larger than in the past. It has autonomous powers and a much broader mandate as 'developmental local government', committed to working with citizens and groups within the community to find ways to meet their social, economic and material needs.

IDPs are seen as the key planning tools for municipalities, but these are also expected to share the work of provincial and national departments. They are strategic documents and give direction to what programmes and projects should be undertaken and also to budgets. IDPs are expected to involve participation, drawing community groups and stakeholders (business, NGOs, provincial and national government and parastatals) into discussion about development priorities, problems and solutions. They are seen increasingly as important forums where the various spheres of government (and others) come together to agree on the development direction of a municipality and the actions of each department in the local area (Sithole et al., 2007)

Like many municipalities, the NMMDM has focused its efforts to eradicate extreme poverty and hunger by using IDPs as a super plan to give an overall framework for development. It aims to coordinate the work of local and other spheres of government in a coherent plan to improve the quality of life for all the people living in the area (NMMDM, 2012). The NMMDM IDP takes into account the existing conditions, problems and resources available for development. This looks at the economic and social development for the area as a whole.

\section{Theory of Multidimensional Scaling}

This study used Multidimensional Scaling (MDS) to study poverty in NMMLM. MDS is the proximity matrix, arising either directly from experiments in which subjects are asked to assess the similarity of pairs of stimuli, or indirectly, as a 
measure of the correlation or covariance of the pair of stimuli derived from their raw profile data (Everitt \& Dunn, 2001). This technique is also defined as a set of techniques for analysis of proximities (similarities or dissimilarities) that reveal the structure and facilitates visualization of high dimensional data (Svetlana et al. (2013). One of the objectives of this technique is to find a lower dimensional representation for a set of objects by representing the inter-object proximities as distances in some lower dimensional space. In this study, the authors are generally interested in uncovering any structure or pattern that may be present in the levels of poverty among the five local municipalities of the NMMDM, in particular to identify the dimensions on which MDS makes its similarity judgements.

Since the NMMDM aims to eradicate poverty, MDS may help identify local municipalities with similar levels of poverty. This information may be used to formulate appropriate strategic plans and policies of interest to the respective local municipalities. The use of MDS helps in producing different configurations of points in a graphical display. This method also helps in searching for lower dimensional space in which points in the space represent the objects (poverty variables in this study). Cox \& Cox (2001) define MDS as any multivariate data analysis technique which produce a graphical representation of objects. This method is applied to both the metric and nonmetric data to search for the lower dimensional space and the associated configuration of points. This study uses metric MDS and this requires dissimilarity coefficients with matric properties. The dissimilarity is measured with the proximity between objects. These measures of dissimilarity are used to compare variables. Proximities for each pair of objects are organised into a square matrix of proximities. This matrix is assumed to be symmetric with minimum distances (or maximum similarities) on the diagonal. This assumption only holds if the proximities are calculated from patterns of activities.

In this study Euclidean distances are calculated for each pair of variables measuring poverty in the NMMDM. Eldelman et al. (1998), Hiramatsu et al. (2011), Borg \& Groenen (2005) and Welchew et al. (2002) define proximity matrix for a pair of object as pairwise Euclidean distances. Municipalities are considered similar to one another if the distance measure between them is small, otherwise they are considered dissimilar. This may help identify municipalities with low, moderate of high poverty levels and will ultimately help in finding suitable groupings according to how poverty is affecting them. For example, points for municipalities in this lower dimensional (usually two dimensional) space that lie close to one another will indicate that these corresponding municipalities have a greater similarity in relation to poverty and may be grouped together.

To determine the appropriateness of the number of dimensions, a scree plot is used. A scree plot shows the points of dimensionality versus fit and is useful in selecting the appropriate number of dimensions when there is a clear elbow. The overall fit of the number of dimensions is confirmed with a stress measure. Increase in the number of dimensions reduces stress values. Stress measure is used to assess the goodness of fit of the number of dimensions. It is a proportion of the variance of the disparities not accounted for by the MDS model. This proportion is used to determine the model's goodness of fit. It also helps to determine the appropriate number of dimensions to include in the model. The following equations are used to define this measure.

$$
\text { Raw Stress }=\sum\left(d_{i j}-\hat{d}_{i j}\right)^{2}
$$

Where:

$d_{i j}=$ distance between variables $i$ and $j$ in the configuration

$d_{i j}=$ those values which minimize the stress, subject to the constraint the $d_{i j}$ 's have the same rank order as the input data.

However, raw stress is a very unsatisfactory measure of the fit. Configurations, which are identical in all but size, will have different values of stress. By normalizing the raw stress, it is possible to compare configurations by making stress independent of the size or scale of the configuration and normalizing its value between 0 (perfect fit) and 1 (worst possible fit). The two most commonly used normalizing factors are:

The Sum of squared distances:

Sum of squared differences $\sum d^{2}{ }_{i j}$ between the distances and their $\sum_{i}\left(d_{i j}-\hat{d}_{i j}\right)^{2}$ average:

Thus the two measures of normalized stress are:

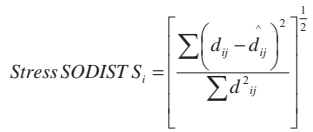

$$
\text { STRESS SODEV } S_{2}=\left[\frac{\sum\left(d_{i j}-\hat{d}_{i j}\right)^{2}}{\sum d^{2}{ }^{\frac{1}{2}}}\right]^{\frac{1}{2}}
$$

Where:

$\overline{\mathrm{d}}=$ mean of all $d_{i j}$ 's 
Stress is minimized when the objects are placed in a configuration so that the distances between the objects best match the original distances (Hair et al. 2010). Stress less than or equal to 0.1 is excellent and greater than or equal to 0.15 is not tolerable.

\section{The Research Study Methodology}

A quantitative approach was used in this study with secondary data from the department of social development. Quantitative methods seek regularities in human lives by separating the social world into empirical components called variables which can be represented numerically as frequencies or rates, whose associations with each other can be explored by statistical techniques and accessed through researcher-introduced stimuli and systematic measurement (Payne \& Payne, 2004). This approach best suits the study's analysis of local municipalities' proximities.

Also, a multivariate data analysis technique called multidimensional scaling (MDS) was used to analyse the data. MDS refers to a series of techniques that help a researcher provide a visual representation of the pattern of proximities (i.e. similarities or distances) among a set of objects (Hair, et al., 2010).This reduces the number of strategic plans and policies that need to be formulated according to the number of clustered local municipalities. The district municipality, because of the reduced focus areas, can adequately deal with its poverty eradication mandate.

MDS analysis was performed in the following manner:

- Gathering proximities of similarity across the entire set of objects to be analysed was done first.

- MDS techniques were used to estimate the relative position of each object in multidimensional scaling, and lastly,

- Identification of and interpretation of axes in the dimensional space with regard to perceptual and objective attributes was done.

\subsection{The research method and data}

A MDS method was used to describe the relationship between levels of poverty in the local municipalities. However the application of the MDS methods to the local municipalities is not a straightforward task. There are two measures of proximity in a statistical context, that is, similarity and dissimilarity, which are used to measure how similar and dissimilar the local municipalities are to each other (Roux, 2008). Measures of similarity (dissimilarity) between the local municipalities must be calculated and theoretically, there are at least 43 possible similarity coefficients that could be used (Hubàlek, 1982).

The choice of similarity coefficients is very important as it will heavily influence the graphical displays produced by the MDS methods. Some of these similarity coefficients will be more appropriate to use than others, depending on the actual data set. These similarity coefficients will provide some measurement of how similar (dissimilar) levels of poverty are to each other. Several MDS methods can be applied to the data set and these methods can produce different configurations of points in the graphical displays (Roux, 2008). However, the display space for metric MDS methods chosen is the Euclidean. This means that the display will have a direct distance-like interpretation. Points representing poverty levels of the local municipalities that lie close to each other will indicate that there is a relationship and similarity between the local municipalities. The reverse is also true about dissimilarity of municipalities.

\subsection{Study population and sample}

The North West Province population data was used as the population for this study. Of the North West Province's four district municipalities and 20 local municipalities, only the NMMDM was used as the study sample. Poverty levels of the five local municipalities in the NMMDM were studied as a reflection of poverty levels in the whole population of the North West Province. The NMMDM has five local municipalities and 10 characteristics of poverty were identified for analysis. Stratified random sampling method was used, where the population is partitioned into sub-populations or strata, which are then independently sampled.

A stratified random sample is one obtained by separating the population elements into non-overlapping groups, called strata, and then selecting a simple random sample from each stratum (Scheaffer et al., 2006). The 10 variables measuring poverty are: personal income, per capita income, per household income, disposable income, unemployment, formal dwelling backlog, sanitation backlog, water backlog, no electricity and no formal refuse removal. The results from the strata were then combined to estimate population parameters such as mean. 
Statistical Package for Social Sciences version 21 (SPSS) was used as a statistical analytical tool. SPSS is a quantitative statistical application, widely used for a variety of disciplines. In this study it was used to manage, analyse, manipulate and display data quickly and accurately. More often, SPSS is used as a confirmatory type of analysis tool.

\section{Study Data Analysis}

\subsection{Measure of Sampling Adequacy}

Measure of sampling adequacy is calculated both for the entire correlation matrix and each individual variable, evaluating the appropriateness of the sample. The Kaiser-Meyer-Olkin (KMO) measure of sampling adequacy was used to test the adequacy of sample used in this study. This measure was first introduced by Kaiser (1970) and modified by Kaiser \& Rice (1974). KMO values above 0.5 for either the entire matrix or an individual variable indicate appropriateness (Hair, et al. 2010) or sample adequacy. KMO is calculated as follows:

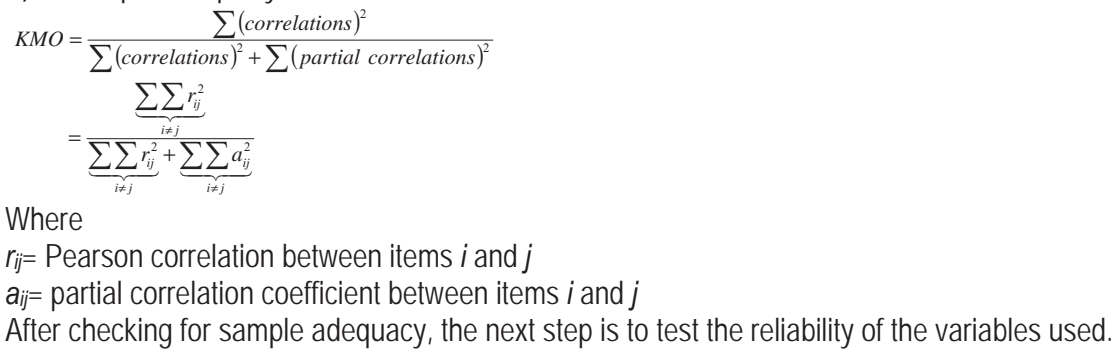

\subsection{Reliability of variables}

The diagnostic measure of reliability used in this study is Cronbach's Alpha introduced by Cronbach in 1951. This is a measure of internal consistency, i.e. how closely related a set of items are as a group. It is a measure of reliability that ranges from 0 to 1 , with values of 0.6 to 0.7 deemed the lower limit of acceptability (Hair et al. 2010). Cronbach's basic equation for alpha is stated as follows:

$$
\alpha=\frac{k r}{1+(k-1)}
$$

Where $k$ is the average correlations between the variables and $r$ is the number of variables. These theoretical statistical tests were applied to the data set as discussed below.

\section{Preliminary Data Analysis}

Preliminary data analysis was done to make sure the data used in the study was relevant and measures poverty in the local municipalities under investigation. These results are presented on Table 1 below. The analysis starts by checking the adequacy of the sample and the reliability of the variables..

\subsection{Checking the adequacy of sample}

The results on Table 1 confirms the adequacy or inadequacy of the sample used in this study.

Table 1: Kaiser-Meyer-Olkin (KMO) Measure of Sampling Adequacy.

\begin{tabular}{|l|c|c|}
\hline \multicolumn{2}{|c|}{ Kaiser-Meyer-Olkin (KMO) Measure of Sampling Adequacy. } & $\mathbf{0 . 5 5 2}$ \\
\hline \multirow{3}{*}{ Bartlett's Test of Sphericity } & Approx. Chi-Square & 85.574 \\
& Df & 10 \\
\cline { 2 - 3 } & Sig. & 0.000 \\
\hline
\end{tabular}

The $\mathrm{KMO}$ is greater than a bench mark of 0.5 indicating that the sample used is adequate. 


\subsection{Measuring reliability of Variables}

Summarised below is the reliability results for the variables used in the analysis.

Table 2: The reliability of the poverty variables.

\begin{tabular}{|c|c|}
\hline \multicolumn{2}{|c|}{ Reliability Statistics } \\
\hline Cronbach's Alpha & N of Items \\
\hline 0.867 & 10 \\
\hline
\end{tabular}

The Cronbach's alpha is greater than 0.7 and as stated earlier; this is a good indication that the variables selected for the analysis measure the same construct.

\subsection{Determining Poverty dimensions}

This section identified the number of dimensions explaining the 10 poverty levels in the 5 local municipalities under study. The results are presented on Table 3:

Table 3: Dimensionality of the poverty variables

\begin{tabular}{|c|c|c|}
\hline Dimension & Eigen Values & Cumulative \% \\
\hline 1 & 7.104 & 71.039 \\
\hline 2 & 2.376 & 94.800 \\
\hline 3 & 0.464 & \\
\hline 4 & 0.056 & \\
\hline 5 & $5.117 \mathrm{E}-016$ & \\
\hline 6 & $2.381 \mathrm{E}-016$ & \\
\hline 7 & $7.889 \mathrm{E}-017$ & \\
\hline 8 & $-1.201 \mathrm{E}-016$ & \\
\hline 9 & $-1.839 \mathrm{E}-016$ & \\
\hline 10 & $-3.911 \mathrm{E}-016$ & \\
\hline
\end{tabular}

The results reveal two eigen-values greater than one. This means that the 10 poverty levels can better be represented in two dimensions. The two eigen-values account for $94 \%$ of the total variation, with the first dimension accounting for the highest variance of about $71 \%$. This means that more of the municipalities are classified in the first dimension than the second. Next, the initial and optimal solutions are given in an attempt to address the objectives of the study. On that note, the next section discusses the objectives of this study and how the results addressed them.

\section{Research Study Objectives Revisited}

\subsection{Objective 1: To determine the levels of poverty in the local municipalities}

\subsubsection{Deriving the Solution and Assessing Overall Fit}

In assessing these poverty levels, the following stages were followed:

\subsubsection{Initial Solution}

This is a starting point in selecting the best spatial configuration for the data (Hair, et al., 2010). The initial solution is derived from the original data to identify the fit of the possible dimensionality of the data. Table 4a below summarises the results of initial solution showing how well the 5 municipalities are fitted in a two dimensional map. For a good fit, we want to see low measures of stress (less than 0.15 ) and values close to 1 for dispersion accounted for (D.A.F) and Tucker's coefficient of congruence. 
Table 4a: Stress and Fit Measures

\begin{tabular}{|l|c|}
\hline Normalized Raw Stress & $\mathbf{0 . 0 0 0 2 7}$ \\
\hline Stress-I & $0.01650^{\mathrm{a}}$ \\
\hline Stress-II & $0.03977^{\mathrm{a}}$ \\
\hline S-Stress & $0.00076^{\mathrm{b}}$ \\
\hline Dispersion Accounted For (D.A.F.) & $\mathbf{0 . 9 9 9 7 3}$ \\
\hline Tucker's Coefficient of Congruence & $\mathbf{0 . 9 9 9 8 6}$ \\
\hline PROXSCAL minimizes Normalized Raw Stress. & \\
\hline a. Optimal scaling factor $=1.000$. & \\
\hline b. Optimal scaling factor $=1.003$. & \\
\hline
\end{tabular}

The normalised raw stress is less than 0.15 implying that the results are good for the model's goodness of fit. Tucker's Coefficient of Congruence and the dispersion accounted for are close to 1 . The study can therefore determine the two dimensions to include in the model. This confirms the results on Table 3 that the 10 poverty variables can better be represented by the two dimensions.

Table $4 \mathrm{~b}$ shows the estimates of the five municipalities and the estimates of dimensions they are associated with.

Table 4b: Initial coordinates local municipalities.

\begin{tabular}{|l|c|c|}
\hline \multirow{2}{*}{\multicolumn{1}{|c|}{ Municipality }} & \multicolumn{2}{c|}{ Dimension } \\
\cline { 2 - 3 } & 1 & 2 \\
\hline Mafikeng_L_M & 1.002 & -.218 \\
\hline Ratlou_L_M & -.472 & -.320 \\
\hline Ramotshere_Moiloa_L_M & .009 & .078 \\
\hline Ditsobotla_L_M & .034 & .548 \\
\hline TSwaing_L_M & -.555 & -.089 \\
\hline
\end{tabular}

As the results show, Mafikeng is associated with high $(+1.002)$ but not extreme levels of poverty with Ditsobotla on the extremely high position (+0.548), Tswaing and Ratlou are on the extremely low positions ( -0.555 and -0.472$)$ respectively and lastly Ramotshere Moiloa on the moderate position. The two dimensions above are clearly shown on the perpetual map below. Dimension 1 may be interpreted as the presence of high and dimension 2 as low poverty levels. The group at the upper right of the map comprise municipalities with extremely high poverty levels. The upper left is a position of municipalities associated with moderate levels. Toward the lower left are municipalities with extremely low levels of poverty. Finally, at the lower right are those municipalities with high but not extreme levels.

Figure 1: Initial perceptual map of the local municipalities

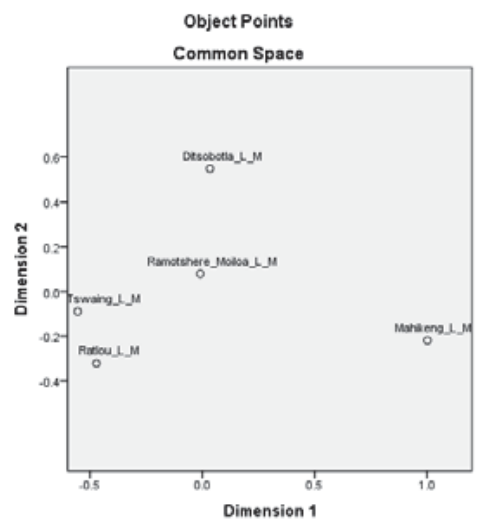

As illustrated in the Figure 1, Mafikeng appear on the lower right part of Dimension 2 and Ratlou and Tswaing are situated on the lower left positions of Dimension 1. This may mean that Mafikeng is associated with high but not extreme 
levels of poverty. The opposite applies to Ramotshere Moiloa. Ratlou and Tswaing are associated with moderately low and Ditsobotla with extremely high levels of poverty. A brief description of the demographic, economic, social and geographic status of these municipalities could assist the reader in understanding these results better.

\subsection{Characteristics of the five local municipalities}

Mafikeng Local Municipality is the biggest in terms of the number of wards and Ratlou is the smallest. Ramotshere occupies $27 \%$ of the total hectares making it the area with the largest portion of land. Mafikeng occupies $13 \%$ of the land. The latter has the smallest portion of land although it represents the highest Gross Value Added (GVA) figures and highest population in the District. In terms of population and poverty levels, Mafikeng has $34 \%$ of the total population and $33 \%$ of the minimum level income earners, thus giving it the largest population density and the local municipality with the largest underprivileged population. Ratlou Local Municipality has 14\% of the total population and $9 \%$ of them are below minimum living income earners. This makes this municipality the region with the least underprivileged population segment both in percentage and numbers. The Mafikeng and the Ditsobotla Local Municipalities are the regions with the highest number of people that have access to basic services with the latter having $38 \%$ of unemployment rate. This makes it the area with the largest unemployment figure in the district. Tswaing Local Municipality has the least unemployment rate of $11 \%$. In terms of economy, the Mafikeng Local Municipality contributes to $40 \%$ of the districts economy, since it is the highest GVA whilst Ratlou contributes $9 \%$. This brief can be used to understand the perceptual map above and the results of the second objective of this study.

\subsection{Objective 2: To determine similarities among local municipalities}

Table 5 represents the proximity matrix of the poverty levels of the five local municipalities. The intention is to identify the municipalities with similar poverty levels looking at the coefficients of the matrix. The greater the coefficient of the proximity matrix, the more dissimilar the local municipalities are and the opposite is true.

Table 5: Proximity Matrix

\begin{tabular}{|l|c|c|c|c|c|}
\hline & Mafikeng & Ratlou & Ramotshere Moiloa & Ditsobotla & Tswaing \\
\hline Mafikeng_L_M & 0.000 & & & & \\
\hline Ratlou_L_M & 1.477 & 0.000 & & & \\
\hline Ramotshere_Moiloa_L_M & 1.054 & 0.610 & 0.000 & & \\
\hline Ditsobotla_L_M & 1.234 & 1.005 & $\mathbf{0 . 4 7 2}$ & 0.000 & \\
\hline Tswaing_L_M & 1.562 & $\mathbf{. 2 4 6}$ & $\mathbf{0 . 5 7 1}$ & 0.867 & 0.000 \\
\hline
\end{tabular}

Mafikeng and Ditsobotla local municipalities have the highest coefficients when compared with other local municipalities, implying that the two have the highest levels of poverty. Other local municipalities not mentioned are dissimilar to these two. Ramotshere Moiloa, Tswaing and Ratlou municipalities have coefficients $0.472,0.571$ and 0.246 respectively, implying the closeness of these three. These three municipalities may be clustered together.

\subsubsection{Optimal Solution}

This is a final point in selecting the best spatial configuration for the data in MDS. It is also the process of simultaneously transforming proximity data and representing the transformed data by a geometrical (often a Euclidean distance) model (The Cambridge dictionary of statistics, 2006). The optimal solution is derived from testing the dimensionality of the proximity matrix provided by the initial solution. The results of this solution are not presented here. There are small insignificant changes in the results of this solution. The normalised raw stress $(0.00012)$, dispersion accounted for (0.99988) and Tucker's coefficient of congruence (0.99994) still show that the results are fitted well in a two dimensional map as implied by the initial solution. The results of the proximity matrix also confirm the similarities accounted for when interpreting the initial matrix solution. These results are consistent with suggestions by Hair, et al., (2010).

The scree plot below is used to determine the appropriate dimensionality. The stress value is plotted against different numbers of dimensions. The dimension with the lowest stress level from the scree plot, i.e. the point closest to the horizontal line, is the most appropriate dimension. 
Figure 2: Scree plot

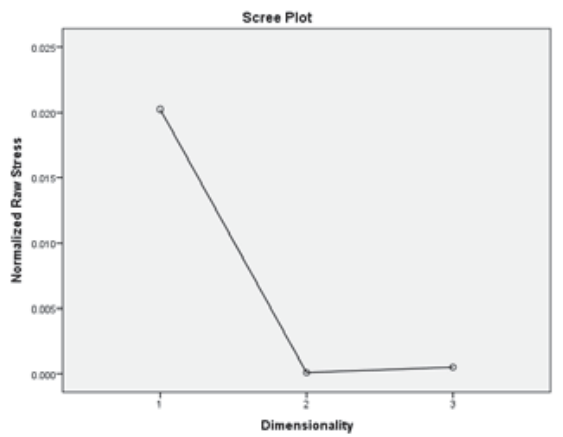

We see from the graph that stress increases as the number of dimensions is reduced. The biggest increase is from 2 to 1 dimension. The sharp change in the slope at dimension 2 shows that a visual representation in two dimensions is the best for this distance matrix.

\section{Discussions, Conclusion and Recommendations}

The analysis of data showed the results of the 5 local municipalities been clustered into two with Mafikeng and Ditsobotla forming cluster one. These two municipalities are defined by high level of poverty with Ditsobotla associated with extremely high levels. Ratlou Tswaing and Ramotshere Moiloa form another cluster associated with low levels of poverty. However, the latter occupies the upper left position of the dimension which is defined as moderately low poverty levels. These results are illustrated on the perpetual map of Figure1. With the reduced number of local municipalities, the district municipality may now focus on the few combined clusters. This may result in a concerted increase in distribution of resources and consequently, the reduction in poverty.

Based on the findings, Ditsobotla local municipality contributes the most to the poverty rate of the NMMDM, while Ramotshere Moiloa local municipalities have the least contribution. It is therefore recommended that the municipalities with high poverty levels be closely monitored. The government may embark on implementing strategies that target poverty reduction and later eradication. Relevant municipal managers from these poverty stricken municipalities may also investigate measures other municipalities are using to prevent high levels of poverty in their municipalities. This could be a solution to the entire district. The main aim of the district municipality is to improve the quality of its community's standard of living through the implementation of formulated policies. The study on this note therefore make another recommendation to the district municipality to encourage the local municipalities with similarities to work together in the development of strategic plans and policies that will assist them in eradicating extreme poverty and hunger effectively and efficiently. This may be achieved by developing realistic projects that will benefit communities in need based on the resources allocated.

It is further recommended that the resources be distributed according to the levels of poverty in the five local municipalities and the needs of their communities. With Ditsobotla local municipality identified as the least serviced and most impoverished local municipality, the NMMDM should identify it as the local municipality where most of the municipal funds should be spent. The above recommendations may also assist the district municipality to efficiently account for the municipal funds. Lastly, it is recommended that statistical techniques used for the same purpose as MDS such as Cluster Analysis be used in confirming the results of this study. The study can in the future focus on individual local municipalities in order to identify the poverty criteria among the 10 investigated in this study that affects each municipality the most.

\section{References}

Borg, I. \& Groenen, P.J.F. (2005). Modern multidimensional scaling: Theory and Applications. Springer press, New York.

Cox, T.F. \& Cox, M.A.A. (2001). Multidimensional Scaling. Chapman and Hall.

Cronbach L. (1951). Coefficient alpha and the internal structure of tests. Psychomerika, 16, PP. 297-334.

De Villiers B. 2008. Review of Provinces and Local Governments in South Africa: Constitutional Foundations and Practice, Konrad Adenauer Stiftung, Johannesburg 59-82.

Devenish, G.E. (2005). The South African Constitution. LexisNexis, Butterworths, 0409021849, 9780409021844. 
Edelman, S., Grill-Spector, K. Kushnir, T. \& Malach, R. (1998). "Toward direct visualization of the internal shape representation space by fMRI, (special issue on Cognitive Neuroscience of Object Representation and Recognition" Psychobiology, 26 (4), PP. $309-321$.

Everitt, B.S. (2007). The Cambridge Dictionary of Statistics. The Indian Journal of Statistics, 69 (4), $\quad$ PP. 887-888

Everitt, B.S. \& Dunn, G. (2001). Applied Multivariate Data Analysis. Arnold, London.

Govender, K. (2012). School feeding in South Africa. Strategies to Overcome Poverty and Inequality, Presented at the Conference at the University of Cape Town

Hair, J.F., Black, W.C., Babin, B.J. \& Anderson R.E. (2010). Multivariate Data Analysis. Prentice Hall, Upper Saddle River, New Jersey.

Harrison, P. (2006). Integrated Development Plans and Third Way Politics. In U. Pillay, R. Tomlinson \& J. D. Toit (Eds.), Democracy and delivery (PP. 186-207), HSRC Press.

Hiramatsu, C., Goda, N \& Komatsu, H. (2011)."Transformation from image-based to perceptual representation of materials along the human ventral visual pathway," Neurolmage, 57 (2), PP. 482-494.

Hubalek, Z. (1982). "Coefficients of Association and Similarity, Based on Binary (Presence-Absence) Data: An Evaluation", Biological Reviews, 57 (4), 669-689.

Kaiser, H.F. (1970). A second generation little jiffy. Psychometrika, 35 (4), 401-415.

Kaiser, H.F. \& Rice, J. (1974) Little jiffy, mark iv. Educational and Psychological Measurement, 34 (1), $111-117$.

Khumalo, G. (2012). South Africa: Access to HIV Services a Barrier for Disabled People. SANews.co.za, Tshwane.

Madiba, M. Gauteng puts more punch into fighting poverty. Vuk'uzenzele. 5, June 2012.

Lehohla P. (2010). Millenium Development Goal (MDG), RSA country's report.

Local Government Municipal Systems Act (32 of 2000).

Mosoetsa, S. (2011). Eating from One Pot (The Dynamics of Survival in Poor South African Households). Wits University Press, South Africa.

Ndungane, N. (2003). A World with a Human Face (A Voice from Africa). Society for Promoting Christian Publishers, Sheldon Press, ISBN 10: 0281054398 / ISBN 13: 978028105.

Ngaka Modiri Molema District Municipality (NMMDM) annual report, 2012. IDP Guide (Know the IDP Process).

Payne, G. \& Payne, J. (2004). Key Concepts in Social Research. London, Sage.

Roux, I. (2008). Application of Cluster Analysis and Multidimensional Scaling on Medical Schemes Data. MCom Thesis, Stellenbosch University.

Scheaffer R.L, Mendenhall W. \& Ott, R.L. (2006). Elementary Survey Sampling. Boston: Prindle, Weber and Schmidt.

Svetlana V.S., Jing, W. \& Douglas. W. H. (2013). Examining Similarity structure: Multidimensional Scaling and Related Approaches in Neuroimaging. Computational and Mathematical Methods in Medicine, 2013, PP. 1-9.

Sithole, P., Sithole, A. \& Williamson, A. (2007). Women, decentralisation and Integrated Q6 Development Planning in South Africa, Human Sciences Research Council, South Africa. Report to the International Development Research Centre (IDRC), Human Sciences Research Council, Canada.

Welchew, D.E., Honey, G.D. Sharma, T., Robbins, T.W. \& Bullmore, E. T. (2002). "Multidimensional scaling of integrated neurocognitive function and schizophrenia as a disconnexion disorder," Neurolmage, 17 (3), PP. 1227-1239. 